\title{
The effect of the fibre orientation of electrospun scaffolds on the matrix production of rabbit annulus fibrosus-derived stem cells
}

\author{
Chen Liu ${ }^{1,2}$, Caihong Zhu ${ }^{1,2}$, Jun Li ${ }^{1}$, Pinghui Zhou ${ }^{1}$, Min Chen ${ }^{3}$, Huilin Yang ${ }^{1,2}$ and Bin $\mathrm{Li}^{1,2}$
}

\begin{abstract}
Annulus fibrosus (AF) tissue engineering has recently received increasing attention as a treatment for intervertebral disc (IVD) degeneration; however, such engineering remains challenging because of the remarkable complexity of AF tissue. In order to engineer a functional AF replacement, the fabrication of cell-scaffold constructs that mimic the cellular, biochemical and structural features of native AF tissue is critical. In this study, we fabricated aligned fibrous polyurethane scaffolds using an electrospinning technique and used them for culturing AF-derived stem/progenitor cells (AFSCs). Random fibrous scaffolds, also prepared via electrospinning, were used as a control. We compared the morphology, proliferation, gene expression and matrix production of AFSCs on aligned scaffolds and random scaffolds. There was no apparent difference in the attachment or proliferation of cells cultured on aligned scaffolds and random scaffolds. However, compared to cells on random scaffolds, the AFSCs on aligned scaffolds were more elongated and better aligned, and they exhibited higher gene expression and matrix production of collagen-I and aggrecan. The gene expression and protein production of collagen-II did not appear to differ between the two groups. Together, these findings indicate that aligned fibrous scaffolds may provide a favourable microenvironment for the differentiation of AFSCs into cells similar to outer AF cells, which predominantly produce collagen-I matrix.
\end{abstract}

Bone Research (2015) 3, 15012; doi:10.1038/boneres.2015.12; Published online: 9 June 2015

\section{INTRODUCTION}

Low back pain (LBP), a condition that affects approximately $80 \%$ of the global population and is generally the result of intervertebral disc (IVD) degeneration. ${ }^{1-2}$ Current clinical treatments for IVD degeneration, including spinal fusion and disc arthroplasty, can alleviate the pain but do not restore the biological and mechanical functions of IVDs. ${ }^{3-4}$ Tissue engineering has evolved into a promising approach for IVD regeneration. ${ }^{5}$ However, without a functioning annulus fibrosus (AF) to confine the nucleus pulposus (NP) and maintain intradisc pressure upon loading, any strategy for IVD regeneration is likely to fail. ${ }^{5-6}$ Therefore, engineering of $\mathrm{AF}$ tissue as an essential IVD component has recently received increasing attention. ${ }^{7}$

Reconstruction of AF using a tissue engineering approach, however, remains challenging, partly because of the intrinsic complexity of AF tissue. ${ }^{8-9}$ Anatomically, AF is a complex fibrocartilage tissue that consists of 15-25 concentric lamellae, which are mainly composed of collagen fibres and glycosaminoglycans (GAGs) such as aggrecan. ${ }^{10-11}$ Lamellar thickness increases with increasing proximity to the disc centre and varies markedly with age: the lamellar thickness of older human discs (from 330 $\mu \mathrm{m}$ near the periphery to $520 \mu \mathrm{m}$ near disc centre) is more than double that of younger discs (140-200 $\mu \mathrm{m}) .{ }^{11}$ AF tissue can be further divided into inner and outer parts according to differences in biochemical, cellular and structural characteristics. The outer AF is highly organised, and the aligned collagen fibres between adjacent lamellae form an angle of $28-44^{\circ}$ with respect to the transverse plane of the spine. ${ }^{1-12}$ The inner AF, as the transition zone of the outer AF and NP, is less oriented. ${ }^{13}$ The cells resident in the outer AF are elongated fibroblast-like cells, which align along the direction of collagen fibres and mainly produce

'Department of Orthopaedics, The First Affiliated Hospital of Soochow University, 188 Shizi St, Suzhou, Jiangsu 215006, China; ${ }^{2}$ Orthopedic Institute, Soochow University, 708 Renmin Rd, Suzhou, Jiangsu 215007, China and ${ }^{3}$ Dan F. Smith Department of Chemical Engineering, Lamar University, Beaumont, TX 77710, USA

Correspondence: Bin Li (binli@suda.edu.cn)

Received: 8 January 2015; Revised: 18 March 2015; Accepted: 14 April 2015 
collagen type I. $^{11,14}$ In contrast, the majority of cells in the inner AF are chondrocyte-like and mainly produce collagen type II and aggrecan. ${ }^{10}$ Correspondingly, major differences in the biochemical composition exist between the two parts of the AF. The outer AF mainly consists of collagen typel, accounting for almost $70 \%$ of its dry weight, while the inner AF is mostly made up of collagen type II and GAGs. Therefore, AF is a typical non-homogenous tissue in which the cellular phenotype, biomechanical components and mechanical properties gradually vary along the radial direction. Ideally, an engineered AF tissue should mimic such region-specific characteristics to achieve biological and biomechanical equivalence with native tissue. However, this issue has been seldom addressed in existing AF tissue engineering studies.

Cells play a central role in determining the quality of engineered tissues. Currently, AF cells or mesenchymal stem cells (MSCs) have been used in the majority of AF tissue engineering studies. ${ }^{9,15-20}$ Recently, we and other groups identified AF-derived stem/progenitor cells (AFSCs) in several species. ${ }^{21-24}$ AFSCs are specific to AF tissue and preferentially differentiate into various types of resident cells in native AF, making them an ideal cell source for AF tissue engineering. They also showed markedly different gene expression and matrix production on scaffolds with different stiffness or microstructures. ${ }^{21,25}$ However, it remains unclear whether the phenotype of these cells changes in response to different scaffold microstructures.

Given that the matrix is mainly composed of collagen fibres that in outer and inner AF tissues have different regularities, we hypothesise that AFSCs seeded on aligned fibrous scaffolds mimicking the outer AF microstructure may produce more collagen-I than cells cultured on random fibrous scaffolds. In this study, we set out to investigate the potential effect of fibre orientation in fibrous scaffolds on the behaviour of AFSCs. We fabricated aligned fibrous scaffolds and random fibrous scaffolds from a biodegradable polyurethane material, poly(ether carbonate urethane)urea (PECUU), using an electrospinning technique. ${ }^{26-27}$ We then cultured AFSCs on the PECUU scaffolds and compared the growth, gene expression, matrix production and cellular mechanics of cells cultured on scaffolds of different regularities.

\section{MATERIALS AND METHODS}

Fabrication of electrospun fibrous PECUU scaffolds

PECUU was synthesised according to the literature ${ }^{26}$ and dissolved in hexafluoro-isopropanol (HFIP) to prepare a 25 $w+\%$ solution. The polymer solution was loaded into a $2 \mathrm{~mL}$ plastic syringe with an $18 \mathrm{G}$ needle and was fed at a constant rate of $0.5 \mathrm{~mL} \cdot \mathrm{h}^{-1}$ using a syringe pump (Longer Pump Co., Ltd). A positive voltage of $10 \mathrm{kV}$ was applied to the needle using a high-voltage power supply (Tianjing
High Voltage Power Supply Co., Ltd). The distance between the collector and the needle tip was set at 15 $\mathrm{cm}$. A rotating disk was used as the collector of electrospun fibrous scaffolds. A rotating speed of $1400 \mathrm{rpm} \cdot \mathrm{min}^{-1}$ was used for fabricating scaffolds composed of aligned fibres, while $200 \mathrm{rpm} \cdot \mathrm{min}^{-1}$ was used for collecting scaffolds with randomly oriented fibres. The scaffolds were vacuum dried overnight prior to subsequent experiments.

Characterization of electrospun scaffolds

The morphology and microstructure of aligned and random PECUU scaffolds were observed using scanning electron microscopy (SEM; S-4800, Hitachi Co. Ltd., Japan). The SEM images were analysed with Image J software to determine the angle distribution (relative to the horizontal axis) and average fibre diameter. The angle distribution was divided from $-90^{\circ}$ to $+90^{\circ}$, while the average diameter was measured from at least 60 randomly chosen fibres in the SEM images.

\section{Cell morphology visualisation}

Rabbit AFSCs were isolated and expanded as previously described. ${ }^{21}$ First-passage AFSCs were seeded on the electrospun PECUU scaffolds in a 96-well plate at a density of $2 \times$ $10^{3}$ cells per well in low-glucose Dulbecco's modified Eagle's medium (DMEM) supplemented with $10 \%$ foetal bovine serum and $1 \%$ penicillin/streptomycin. AFSCs cultured on standard tissue culture polystyrene (TCPS) dishes were used as a control. The cells were cultured in a humidified incubator at $37^{\circ} \mathrm{C}$ and with $5 \% \mathrm{CO}_{2}$. The morphology of cells was visualised by cytoskeleton staining after 7 days of culture on the electrospun scaffolds. For cytoskeleton staining, the cells were rinsed with PBS twice, fixed with $4 \%$ paraformaldehyde for $15 \mathrm{~min}$ and permeabilized with $0.1 \%$ Triton X-100 for 5 min, followed by staining with FITC-phalloidin and DAPI for labelling F-actin and nuclei, respectively. After washing in PBS, the morphology of cells on different scaffolds was visualised under a fluorescence microscope (Zeiss Axiovert 200, Carl Zeiss Inc., Thornwood, NY).

\section{Cell proliferation analysis}

After 1, 3, 5 and 7 days of culture, the cells were washed twice with PBS, and then, $200 \mu \mathrm{L}$ of PBS and $20 \mu \mathrm{L}$ of MTS assay reagent (CellTiter $96 \AA$ AQueous, Promega) were added to each well. After $2 \mathrm{~h}$ of incubation, the absorbance at $490 \mathrm{~nm}$ was measured using a microplate reader (BioTek instruments, USA). For each data point, the cells from five wells were used as duplicates. Cells cultured on TCPS were used as a control.

\section{Gene expression analysis}

The electrospun PECUU scaffolds were cut into pieces fitted to the wells of a 24 -well plate. AFSCs were seeded on the scaffolds at a density of $5 \times 10^{3}$ cells per well. 
The expression of genes was analysed using reverse transcriptase-mediated quantitative polymerase chain reaction (RT-qPCR). Total RNA was extracted from the cells using a TRIZOL isolation system (Invitrogen) following the manufacturer's protocol. Then, the Revert-Aid FirstStrand CDNA Synthesis Kit (Fermentas, K1622) and oligo(dT) primers were applied at $42{ }^{\circ} \mathrm{C}$ for $60 \mathrm{~min}$ on a reverse transcription PCR system (Eastwin Life Science, Beijing) for CDNA synthesis. RT-qPCR was performed on a Bio-Rad CFX96 Real-Time System using the SsoFast EvaGreen Supermix Kit (Bio-Rad). The relative expression level of the collagen-l gene was analysed using the $2^{-\Delta \Delta C \dagger}$ method normalised to the housekeeping gene GAPDH, which served as an internal control. Three duplicates were used for each assay. The sequences of primers used in this study are listed in Table 1.

\section{Biochemical assays}

After 7 days, the supernatants of cells cultured on the electrospun scaffolds were collected. Collagen-l and collagen-ll contents were determined using enzyme-linked immunosorbant assay (ELISA) kits (R\&D Systems, USA) following the manufacturer's protocol. The total GAG content was quantified with the 1,9-dimethylmethylene blue (DMMB) dye-binding assay using a commercially available kit (Genmed Scientifics Inc, USA, GMS 19239.2). ${ }^{28}$ The DNA content was determined using DNA-binding fluorochrome Hoechst 33258 dye. ${ }^{29}$ The matrix synthesis of cells on aligned and random scaffolds was normalised to the corresponding DNA content. Three duplicates were used for each assay.

Immunofluorescence staining

After 7 days in culture, immunofluorescence staining of collagen-I was performed to observe the distribution of this protein in the cells on aligned and random scaffolds. The cell-seeded scaffolds were rinsed with PBS twice, fixed with $4 \%$ paraformaldehyde for 15 min and perforated by methanol at $-20{ }^{\circ} \mathrm{C}$ for $5 \mathrm{~min}$. The non-specific binding was blocked by $4 \%$ bovine serum albumin (BSA) for $30 \mathrm{~min}$ at room temperature. Subsequently, the samples were incubated with a monoclonal anti-collagen-l antibody (Abcam, 90395) at a dilution of $1: 200$ at $4{ }^{\circ} \mathrm{C}$ overnight.

Table 1. Sequences of primers used for RT-qPCR

\begin{tabular}{|c|c|c|}
\hline Gene & Sequence & $\begin{array}{l}\text { Accession } \\
\text { number }\end{array}$ \\
\hline Collagen-I & $\begin{array}{l}\text { Forward: 5'-CTGACTGGAAGAGCGGAGAGTAC-3' } \\
\text { Reverse: 5'-CCATGTCGCAGAAGACCTTGA-3' }\end{array}$ & AY633663 \\
\hline Collagen-II & $\begin{array}{l}\text { Forward: 5'-AGCCACCCTCGGACTCT-3' } \\
\text { Reverse: 5'-TTTCCTGCCTCTGCCTG-3' }\end{array}$ & NM_001195671 \\
\hline Aggrecan & $\begin{array}{l}\text { Forward: 5'-ATGGCTTCCACCAGTGCG-3' } \\
\text { Reverse: 5'-CGGATGCCGTAGGTTCTCA-3' }\end{array}$ & XM_002723376 \\
\hline GAPDH & $\begin{array}{l}\text { Forward: 5'-ACTTTGTGAAGCTCATTT } \\
\text { CCTGGTA-3' } \\
\text { Reverse: 5'-GTGGTTTGAGGGCTCTTACTCCTT-3' }\end{array}$ & NM_001082253 \\
\hline
\end{tabular}

After washing in PBS three times, the samples were further incubated with Cy3-conjugated goat-anti-mouse secondary antibody (1:300, Invitrogen, A10521) for $1 \mathrm{~h}$. In addition, nuclei were stained with DAPI for 5 min. After thoroughly washing in PBS, the collagen-I distribution was visualised under a fluorescence microscope (Zeiss Axiovert 200, Carl Zeiss Inc., Thornwood, NY).

\section{Cell traction force microscopy (CTFM)}

The substrates for performing CTFM were prepared as follows. Glass-bottomed $35 \mathrm{~mm}$ Petri dishes were treated with $0.1 \mathrm{~mol} \cdot \mathrm{L}^{-1}$ sodium hydroxide for 1 day and incubated with 3-aminopropyltrimethoxysilane for $5 \mathrm{~min}$. After washing with deionized water, the dishes were treated with $0.5 \%$ glutaraldehyde for $30 \mathrm{~min}$ and then airdried. A mixed solution containing $6.6 \mathrm{~mL}$ of deionized water, $1 \mathrm{~mL}$ of $40 \%$ acrylamide solution, $0.4 \mathrm{~mL}$ of $0.1 \%$ bis-acrylamide solution and $50 \mu \mathrm{L}$ of FluoSphere beads (Invitrogen, $0.2 \mu \mathrm{m}$ diameter) was prepared and vacuumed for $18 \mathrm{~min}$, followed by the addition and mixing of $4 \mu \mathrm{L}$ of $\mathrm{N}, \mathrm{N}, \mathrm{N}^{\prime}, \mathrm{N}^{\prime}$-tetramethylenediamine and $40 \mu \mathrm{L}$ of ammonium persulfate. Then, $11 \mu \mathrm{L}$ of the mixed solution was added to each dish and kept in the dark at room temperature. After $30 \mathrm{~min}$, a polyacrylamide gel (PAG) with an elastic modulus of $3 \mathrm{kPa}$ was formed. The PAG was then activated using N-sulfosuccinimidyl-6-(4'-azido-2'-nitrophenylamino) hexanoate (Sulfo-SANPAH, Pierce, Rockland, IL) under UV for $10 \mathrm{~min}$, followed by incubation with $150 \mu \mathrm{L}$ of collagen solution (Santa Cruz Biotechnology, Santa Cruz, $\mathrm{CA}, 100 \mu \mathrm{g} \cdot \mathrm{mL}^{-1}$ ) overnight.

For CTFM measurement, AFSCs cultured on the electrospun scaffolds for 7 days were harvested using $0.25 \%$ trypsin and re-plated on the collagen-coated PAG dishes at a density of 3000 cells per dish. The cells were allowed to attach and spread on the gel for $6 \mathrm{~h}$ before cell images were taken. For a selected cell, a phase contrast image and a fluorescence image of the underlying fluorescent beads embedded in PAG ("force-loaded" image) were taken with a fluorescence microscope. After the cell was removed from the substrate, another fluorescence image was taken under the same view ("null-force" image). Cell traction forces (CTFs) were then determined based on the pair of fluorescence images using a MATLAB program according to a published method. ${ }^{30}$ At least 30 duplicates were analysed for each group.

\section{Statistical analysis}

All data are provided as the mean \pm standard deviation (SD) except for CTFM data, which are represented as the mean \pm standard error of the mean (SEM). The statistical analyses were performed by SPSS software. Kruskal-Wallis one-way analysis of variance (ANOVA) tests followed by Tukey post hoc tests were used. Unpaired student's t-tests were also 
used where appropriate. A difference between two groups is considered statistically significant if $P$ is less than 0.05 .

\section{RESULTS}

Fabrication of electrospun fibrous PECUU scaffolds

The fibrous PECUU scaffolds were fabricated using an electrospinning technique. By varying the rotational speed of a rotating pan, which served as the collector for electrospun fibres, aligned fibrous scaffolds or random fibrous scaffolds were prepared (Figure la and b). The fibres in aligned scaffolds were mainly formed within an angle ranging from $-30^{\circ}$ to $30^{\circ}$ with respect to the tangential direction of the rotating pan (Figure 1c), while the fibres in random scaffolds exhibited an almost equal distribution at all angles (Figure 1d).

\section{Cell growth on electrospun scaffolds}

As visualised by cytoskeleton staining using FITC-phalloidin, AFSCs on aligned scaffolds were almost uniformly oriented along the fibre direction and possessed spindle-shaped morphology. Their nuclei also appeared to be stretched (Figure 2a-c). In contrast, AFSCs exhibited irregular cell morphology on random scaffolds (Figure 2d-f). The proliferation of AFSCs on the electrospun PECUU scaffolds was determined using MTS assays at 1, 3, 5 and 7 days of culture. There was no apparent difference in cell proliferation between AFSCs cultured on aligned scaffolds and those on random scaffolds (Figure 3). Interestingly, AFSCs

a
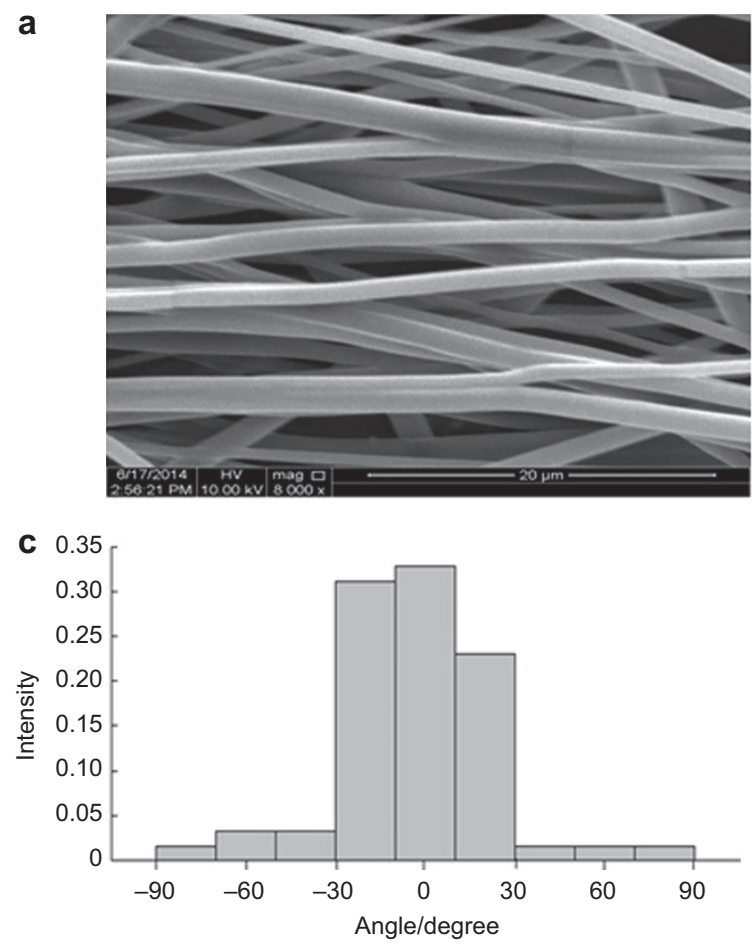

appeared to proliferate much faster on electrospun PECUU scaffolds than on standard TCPS dishes.

\section{Gene expression}

Real-time quantitative PCR was performed to compare the expression of collagen-l, collagen-Il and aggrecan genes in AFSCs cultured on aligned and random scaffolds. After 7 days of culture, the expression level of collagen-l in AFSCs cultured on aligned scaffolds was almost twice that of cells grown on random scaffolds (Figure 4a). The expression of collagen-II was similar in both AFSCs cultured on aligned and random scaffolds (Figure 4b). The expression pattern of aggrecan was similar to that of collagen-l; cells cultured on aligned scaffolds had approximately 0.4 times higher aggrecan gene expression than those grown on random scaffolds (Figure 4c).

\section{Matrix production}

In addition to gene expression analysis, the production of matrix components, including collagen-l, collagen-ll and GAGs, was measured by ELISA. The production of collagen-l by AFSCs cultured on aligned scaffolds was 4.99 $\pm 0.27 \mathrm{ng} \cdot \mu \mathrm{g}^{-1} \mathrm{DNA}$, which was markedly higher than that of AFSCs cultured on random scaffolds $(3.78 \pm 0.37$ $\mathrm{ng} \cdot \mu \mathrm{g}^{-1}$ DNA) (Figure $5 \mathrm{a}$ ). The production of collagen-ll by cells on aligned scaffolds was $6.25 \pm 0.14 \mathrm{ng} \cdot \mu^{-1}$ DNA, which was similar to that of cells on random scaffolds (6.79 $\pm 0.18 \mathrm{ng} \cdot \mu \mathrm{g}^{-1}$ DNA) (Figure $5 \mathrm{~b}$ ). The production of

b
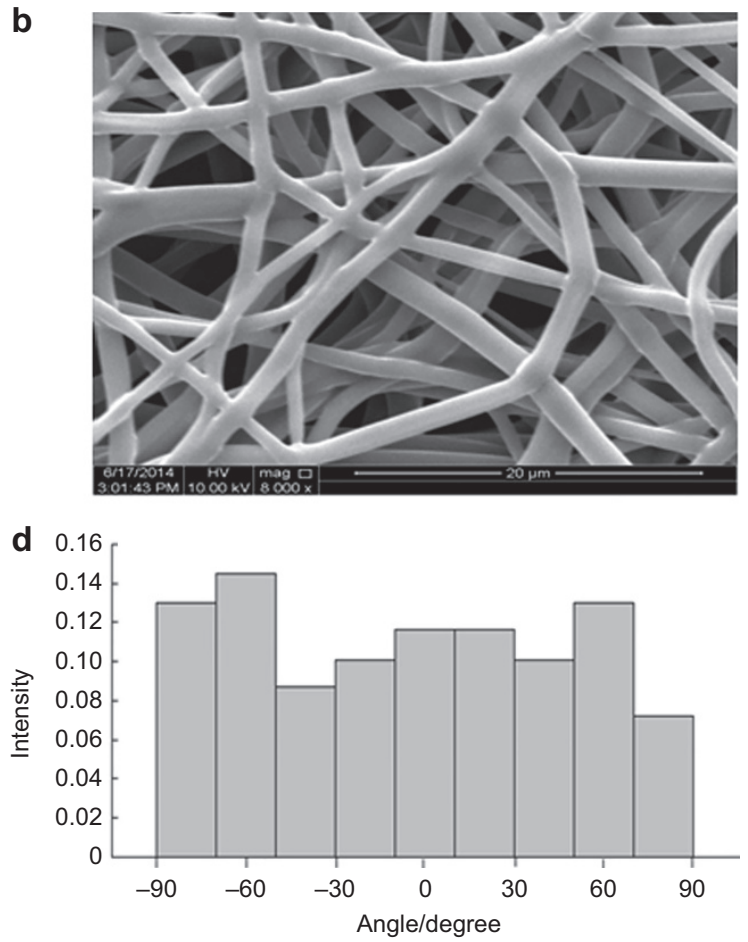

Figure 1. SEM images of electrospun PECUU scaffolds with aligned (a) and random (b) fibrous microstructures. Scale bars, $20 \mu \mathrm{m}$. (c-d) Histograms of angular distribution for aligned and random scaffolds, respectively. 

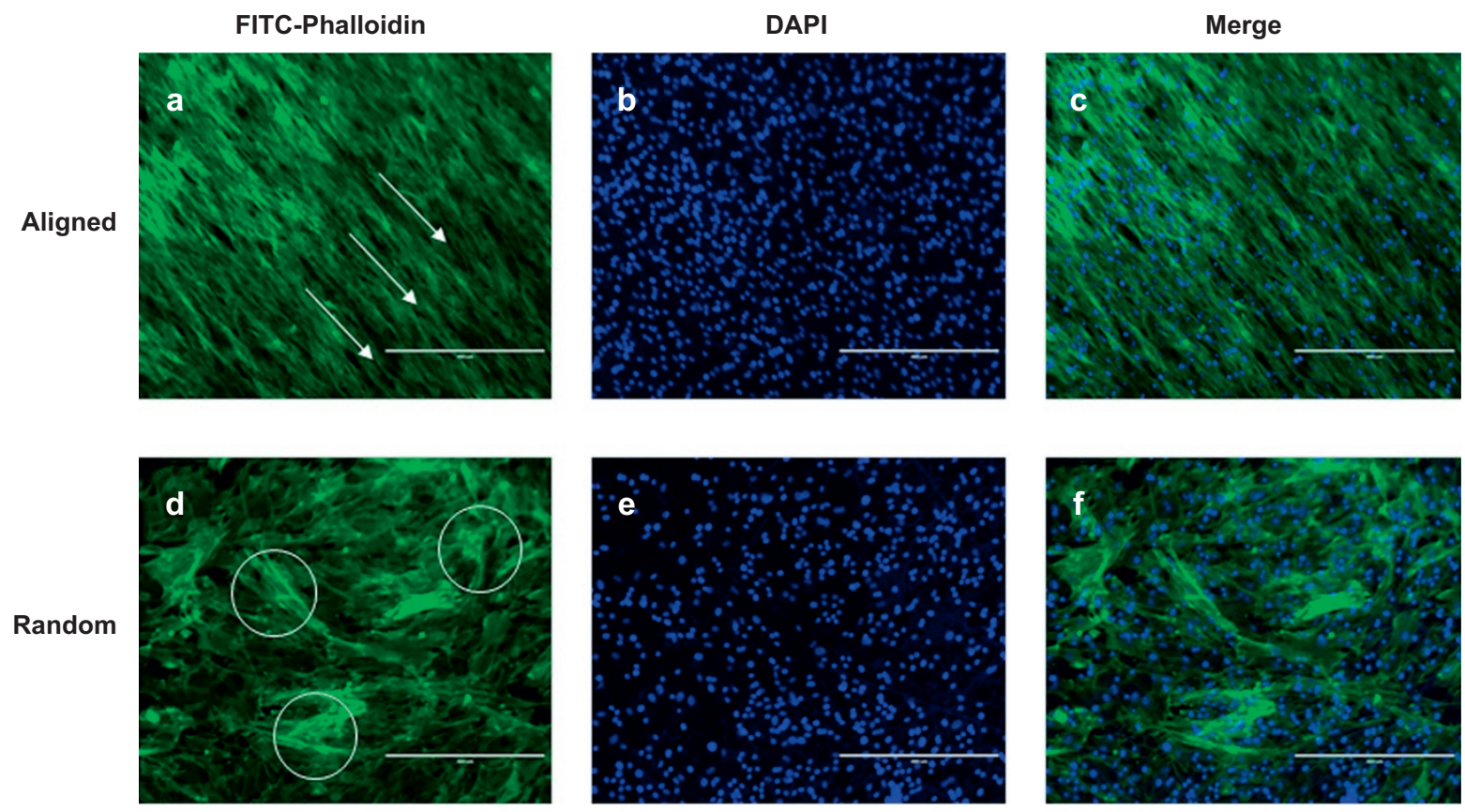

Figure 2. Cytoskeleton staining images of AFSCs with FITC-phalloidin (green) and DAPI (blue) on aligned (a-c) and random (d-f) scaffolds. The orientation of AFSCs along the fibres is indicated by white arrows, while the randomly aligned AFSCs on random scaffolds are shown in white circles. Scale bars, $400 \mu \mathrm{m}$.

GAGs on aligned and random scaffolds was $10.70 \pm 0.30$ $\mu \mathrm{g} \cdot \mu \mathrm{g}^{-1}$ DNA and $5.75 \pm 0.24 \mu \mathrm{g} \bullet \mu \mathrm{g}^{-1}$ DNA, respectively (Figure 5c).

In addition, the distribution of collagen-I protein in AFSCs was assayed by immunostaining. The collagen-I produced by AFSCs on aligned scaffolds was well organised and aligned along the direction of electrospun fibres, whereas the collagen-I produced by AFSCs on random scaffolds was disorganised (Figure 6).

\section{Cell traction force}

The CTFs of AFSCs grown on aligned and random scaffolds were determined using CTFM (Figure 7a). Apparently, cells cultured on aligned scaffolds had lower CTFs compared to those on random scaffolds, at $385.6 \pm 66.2 \mathrm{~Pa}$ and $548.9 \pm$

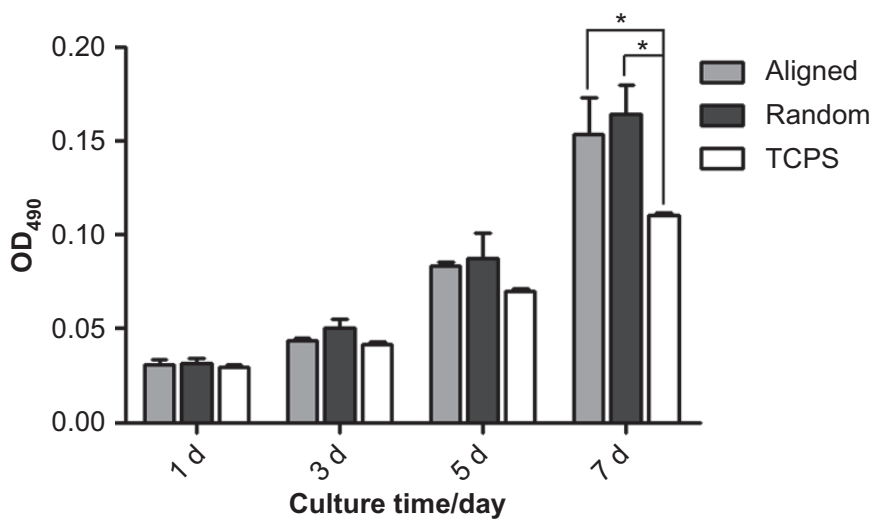

Figure 3. Cell proliferation of AFSCs on aligned and random scaffolds, respectively. Cells grown on TCPS were used as a control.
82.7 Pa, respectively (Figure 7b). Meanwhile, the spreading area of cells on aligned scaffolds was smaller than those on random scaffolds (Figure 7c). In addition, cells on aligned scaffolds had a lower shape index (larger aspect ratio) compared to those on random scaffolds, indicating that cells were more spindle-shaped and stretched when cultured on aligned scaffolds (Figure 7d).

\section{DISCUSSION}

In order to achieve successful tissue engineering, the structure of the scaffold used should closely mimic that of native tissue. Previously, randomly oriented electrospun scaffolds have been predominantly used for AF tissue engineering. ${ }^{31-32}$ However, AF is a highly heterogeneous tissue in which the cellular phenotype, biochemical components, microstructure and biomechanical characteristics gradually change along the radial axis. ${ }^{8}$ The outer AF is a wellorganised tissue with remarkable matrix fibre orientation within each layer. The matrix becomes less oriented in more inward layers. In addition, collagen-I content increases from the inner to the outer AF, while aggrecan and collagen-II levels decrease. . $^{810}$ It has been suggested that the aligned fibrous and angle-ply structure of AF tissue improves its mechanical strength. ${ }^{9}$ However, it remains unclear whether the orientation of scaffold material also affects the cellular behaviour of the newly identified AFSCs. ${ }^{21}$

In this study, we cultured AFSCs on aligned and random fibrous electrospun scaffolds and compared their cellular behaviours, including cell orientation and proliferation. We found that the cells oriented well along the fibre direction 

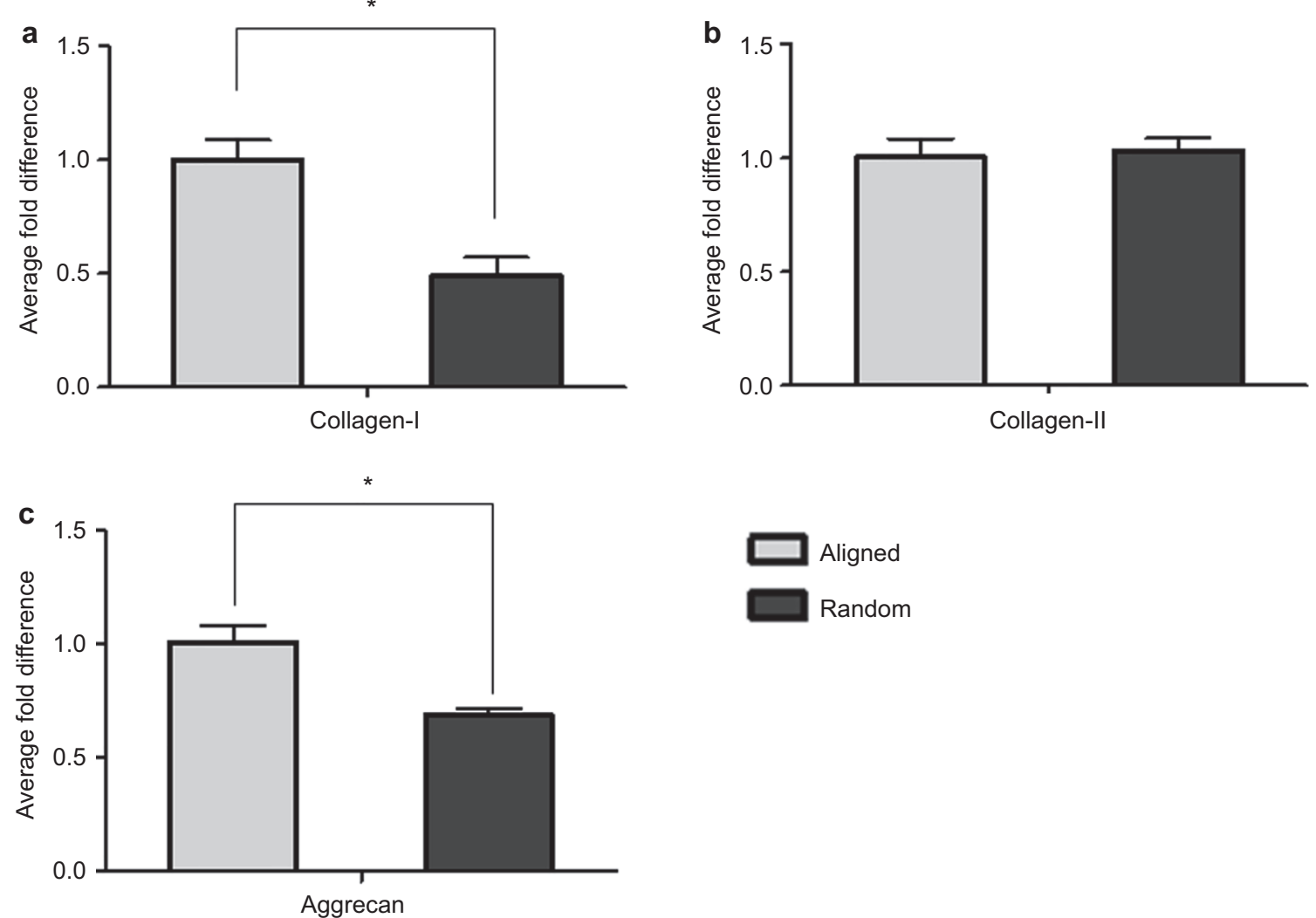

Aligned

Random

Figure 4. Gene expression of collagen-I (a), collagen-II (b) and aggrecan (c) by AFSCs cultured on aligned and random scaffolds for 7 days.
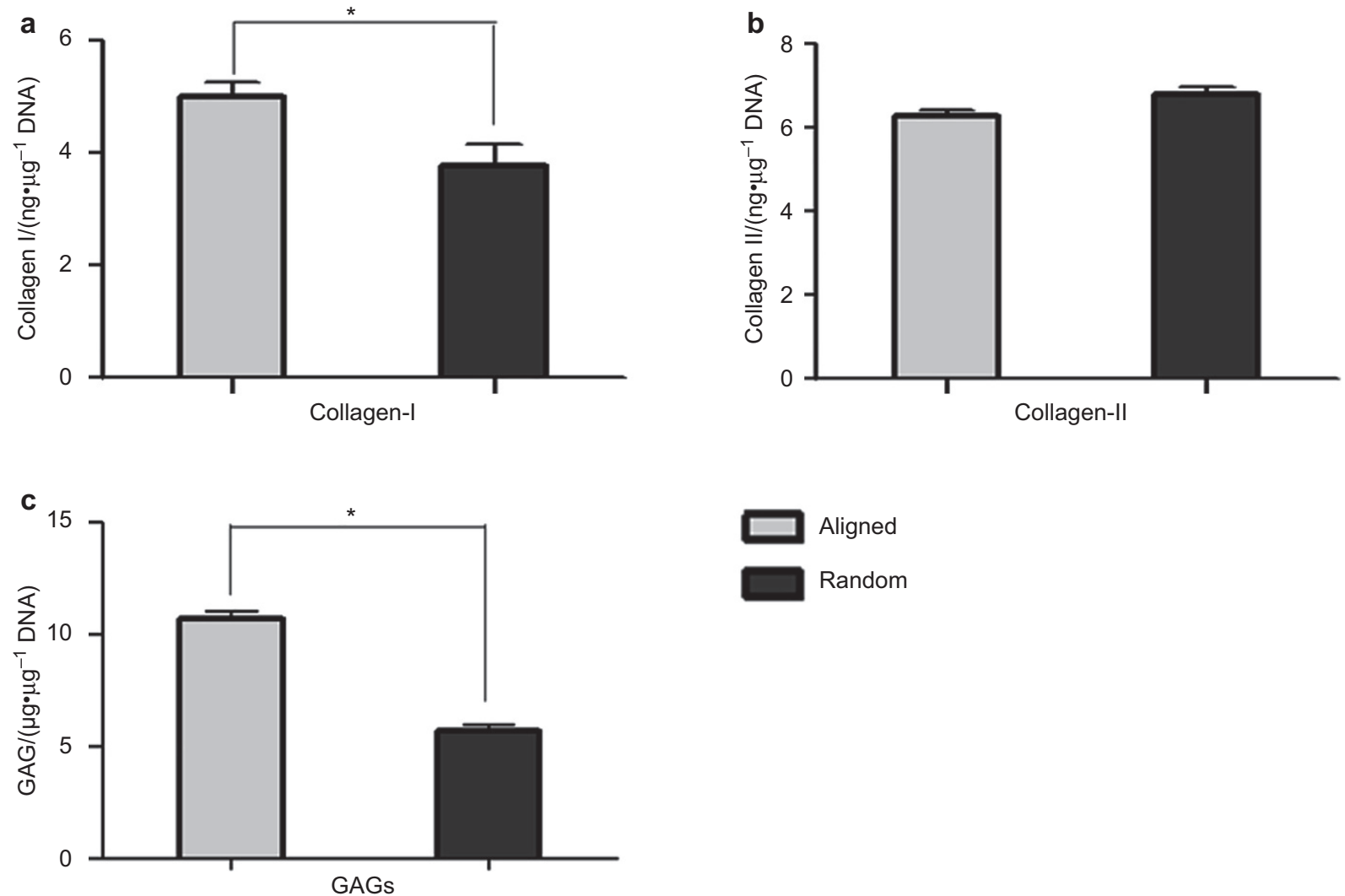

Random

Figure 5. Production of collagen-I (a), collagen-II (b) and GAGs (c) by AFSCs cultured on aligned and random scaffolds for 7 days. Measurements were normalised to DNA content. 

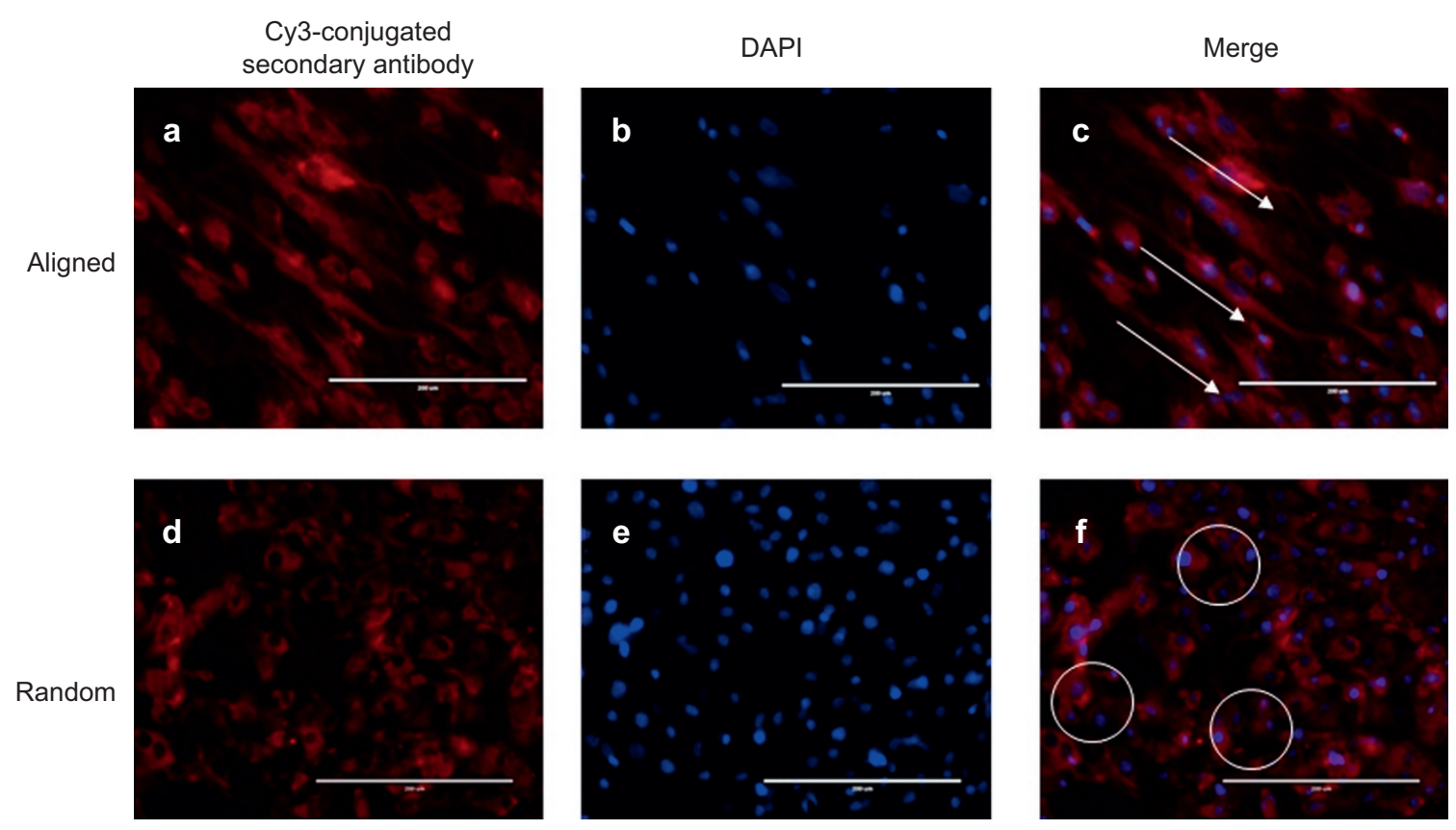

Figure 6. Immunofluorescence staining of collagen-I produced by AFSCs on aligned (a-c) and random (d-f) scaffolds. The orientation of collagen-I along the fibres is indicated by white arrows, while randomly distributed collagen-I on random scaffolds is shown in white circles. Scale bars, $200 \mu \mathrm{m}$.

a
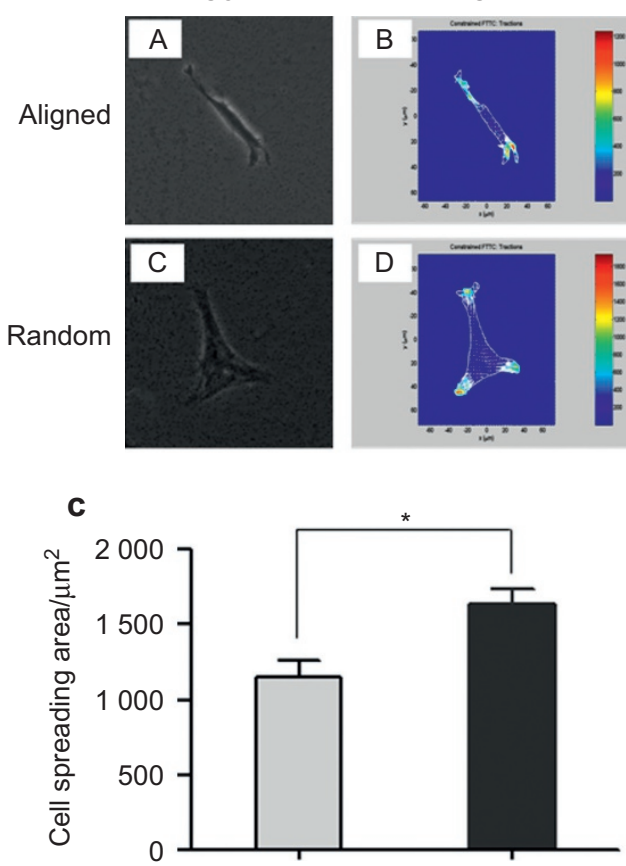

b
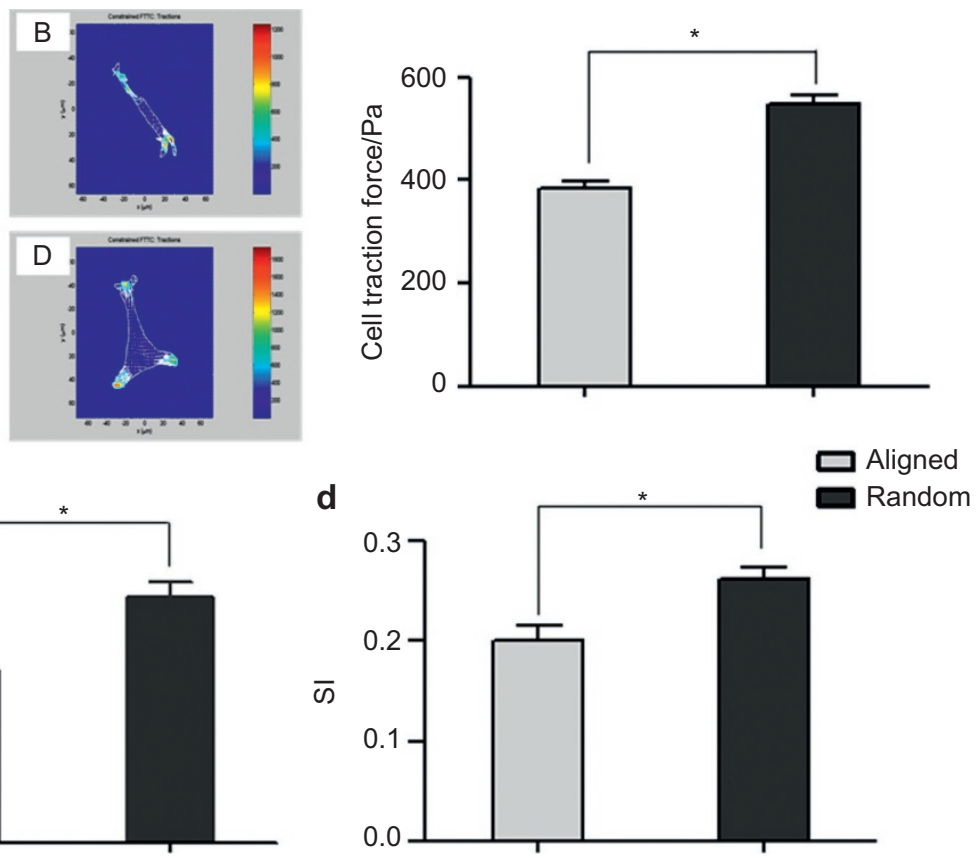

Figure 7. CTFM measurement (a), cell traction forces $(\mathbf{b})$, cell spreading area (c) and shape index (d) of AFSCs cultured on aligned and random scaffolds. In (a), the images on the left (A, C) are phase contrast microscopy images of cells, and the images on the right (B, D) mean CTF maps of corresponding cells.

on aligned scaffolds, while they presented irregular morphology on random scaffolds (Figure 2). This is in agreement with previous studies, which have reported that aligned fibrous scaffolds induced cell orientation. ${ }^{33-34}$ Accordingly, collagen-l secreted by cells on aligned scaffolds was distributed along the direction of fibres, while it was scattered in all directions on random scaffolds (Figure 6). In accordance with the difference in cytoskeleton, the CTFs of cells varied. Due to their spindle-shaped and parallel-aligned cytoskeletons, cells on aligned scaffolds showed a lower CTF compared to those grown on random scaffolds (Figure 7). This echoes our previous 
finding that cells with a larger aspect ratio had a lower CTF. ${ }^{35}$ However, there was no apparent difference in cell proliferation between cells grown on aligned and random scaffolds (Figure 3). Interestingly, AFSCs grew faster on both types of electrospun scaffolds than on TCPS, likely due to their highly porous micro- to nano-scale fibrous structures. ${ }^{36}$

Further, the effect of scaffold fibre orientation on the gene expression and matrix production of AFSCs was studied. In cells cultured on aligned scaffolds, the gene expression and protein production of collagen-l, the major matrix component of AF tissue, was markedly higher than that of cells grown on random scaffolds (Figures 4a and 5a). These results are consistent with those of a previous study, in which AF cells grown in lamellar silk scaffolds showed significantly higher collagen-I gene expression compared to those in porous silk scaffolds. ${ }^{4}$ We also studied the effect of cell shape on collagen-I expression in human tendon fibroblasts and found that elongated cells expressed more collagen-I than less elongated cells, likely as a result of altered cytoskeletal tension-induced mechanotransduction. ${ }^{35}$ It is therefore unsurprising that in this study, AFSCs, which displayed spindle and stretched morphology on aligned scaffolds, expressed more collagen-I than the cells with randomly oriented shapes on random scaffolds. Furthermore, we found that the aligned fibre orientation of scaffolds slightly enhanced the expression of aggrecan and the production of GAGs (Figures 4c and $5 \mathrm{c}$ ), similar to the findings of a previous study. ${ }^{4}$ However, the fibre orientation did not seem to affect the gene expression level and synthesis of collagen type II, implying that collagen type II is not sensitive to scaffold topography (Figures $4 \mathrm{~b}$ and $5 \mathrm{~b}$ ). This is in agreement with a study from Tobias et al., in which the fibre orientation of electrospun scaffolds did not result in major differences in the collagen-ll deposition of articular chondrocytes. ${ }^{37}$ It should be noted that the amounts of major matrix components (i.e., collagen-l, collagen-II and GAGs) in AFSCs cultured on the aligned and random scaffolds were comparable to those in native AF tissue in rabbits. ${ }^{8}$

In addition, the effect of scaffold fibre orientation on the CTFs of AFSCs was measured. CTFs - the mechanical forces generated by the cells - have a profound effect on celIular activities including cell growth and differentiation..$^{38-39}$ Cells have various CTF distributions at different phases of differentiation, and as a result, CTF may serve as a proxy for the phenotypic characterization of cells. ${ }^{40}$ Previously, we found that CTF changed gradually among AF cells in different regions of AF tissue, which provides a convenient way to distinguish region-specific AF cells. ${ }^{8}$ In this study, we have found that AFSCs exhibited lower CTFs on aligned scaffolds than on random scaffolds (Figure 7a). Meanwhile, cells were more spindle-shaped and had a larger aspect ratio when cultured on aligned scaffolds (Figure 7d). This echoes our previous observation that cells at the outer region of AF tissue, which are fibroblast-like and spindle-shaped, have lower CTFs than the relatively round, chondrocyte-like cells found in the inner AF. ${ }^{8}$ This finding seems to imply that the aligned fibrous PECUU scaffolds, by mimicking the microstructure of outer AF tissue, may direct AFSCs to differentiate to an outer AF cell phenotype.

In summary, we have fabricated aligned and random fibrous PECUU scaffolds using electrospinning technology. AFSCs cultured on aligned scaffolds exhibited an elongated shape and produced more and better organised collagen-I and GAGs, but not collagen-Il, compared to the cells seeded on random scaffolds. The findings from this study imply that aligned fibrous scaffolds may provide an inductive microenvironment for AFSCs to differentiate into outer AF cells and produce ECM mimicking the outer region of native AF tissue. This study still has limitations. For example, in native AF tissue, the resident cells are continuously subjected to significant mechanical loads, such as circumferential tension, axial and radial compression, which play a significant role in stem cell differentiation. ${ }^{40-41}$ However, in this study, the AFSCs were cultured under loadfree conditions, which might prejudice the topographical sensitivity of cells. Therefore, in future studies, continuous mechanical loading mimicking the physiological intervertebral situation will be applied during AFSC culture in addition to utilising an aligned scaffold structure. The potential synergistic effects of mechanical loading and scaffold topography, which together have better physiological relevance, on the matrix production of AFSCs will be explored.

\section{Competing interests}

The authors declare no conflict of interest.

\section{Acknowledgements}

This study was supported by the National Natural Science Foundation of China $(81171479,51303120,81471790)$, the China Postdoctoral Science Foundation (2012M521121), the Natural Science Foundation of Jiangsu Province (BK20130335), the Jiangsu Provincial Special Program of Medical Science (BL2012004) and the Priority Academic Program Development of Jiangsu Higher Education Institutions.

\section{References}

1 Luo X, Pietrobon R, Sun SX, Liu GG, Hey L. Estimates and patterns of direct health care expenditures among individuals with back pain in the United States. Spine 2004; 29: 79-86.

2 Krock E, Rosenzweig DH, Chabot-Doré AJ et al. Painful, degenerating intervertebral discs up-regulate neurite sprouting and CGRP through nociceptive factors. J Cell Mol Med 2014; 18: 1213-1225.

3 Wilda $\mathrm{H}$, Gough JE. In vitro studies of annulus fibrosus disc cell attachment, differentiation and matrix production on PDLLA/45S5 Bioglass composite films. Biomaterials 2006; 27: 5220-5229. 
4 Park SH, Gil ES, Mandal BB et al. Annulus fibrosus tissue engineering using lamellar silk scaffolds. J Tissue Eng Regen Med 2012; 6: S24-S33.

5 Hudson KD, Alimi M, Grunert P, Härtl R, Bonassar LJ. Recent advances in biological therapies for disc degeneration: tissue engineering of the annulus fibrosus, nucleus pulposus and whole intervertebral discs. Curr Opin Biotechnol 2013; 24: 872-879.

6 Iatridis JC. Tissue engineering: function follows form. Nat Mater 2009; 8 : 923-924.

7 Bron JL, Helder MN, Meisel HJ, Van Royen BJ, Smit TH. Repair, regenerative and supportive therapies of the annulus fibrosus: achievements and challenges. Eur Spine J 2009; 18: 301-313.

8 Li J, Liu C, Guo Q, Yang H, Li B. Regional variations in the cellular, biochemical, and biomechanical characteristics of rabbit annulus fibrosus. PLoS One 2014; 9: e91799.

9 Nerurkar NL, Baker BM, Sen S, Wible EE, Elliott DM, Mauck RL. Nanofibrous biologic laminates replicate the form and function of the annulus fibrosus. Nat Mater 2009; 8: 986-992.

10 Bruehlmann SB, Rattner JB, Matyas JR, Duncan NA. Regional variations in the cellular matrix of the annulus fibrosus of the intervertebral disc J Anat 2002; 201: 159-171.

11 Marchand F, Ahmed AM. Investigation of the laminate structure of lumbar disc anulus fibrosus. Spine 1990; 15: 402-410.

12 Cassidy JJ, Hiltner A, Baer E. Hierarchical structure of the intervertebral disc. Connect Tissue Res 1989; 23: 75-88.

13 Cassinelli EH, Hall RA, Kang JD. Biochemistry of intervertebral disc degeneration and the potential for gene therapy applications. Spine J 2001; 1: 205-214.

$14 \mathrm{Yu}$ J, Tirlapur U, Fairbank J et al. Microfibrils, elastin fibres and collagen fibres in the human intervertebral disc and bovine tail disc. J Anat 2007; 210: $460-471$.

15 Bowles RD, Gebhard HH, Härtl R, Bonassar LJ. Tissue-engineered intervertebral discs produce new matrix, maintain disc height, and restore biomechanical function to the rodent spine. Proc Natl Acad Sci USA 2011; 108: 13106-13111.

16 Mizuno H, Roy AK, Vacanti CA, Kojima K, Ueda M, Bonassar LJ. Tissueengineered composites of anulus fibrosus and nucleus pulposus for intervertebral disc replacement. Spine 2004; 29: 1290-1297.

17 Driscoll TP, Nakasone RH, Szczesny SE, Elliott DM, Mauck RL. Biaxial mechanics and inter-lamellar shearing of stem-cell seeded electrospun angle-ply laminates for annulus fibrosus tissue engineering. J Orthop Res 2013; 31: 864-870.

18 Koepsell L, Remund T, Bao J, Neufeld D, Fong H, Deng Y. Tissue engineering of annulus fibrosus using electrospun fibrous scaffolds with aligned polycaprolactone fibers. J Biomed Mater Res A 2011; 99: 564-575.

19 Wan Y, Feng G, Shen FH, Laurencin CT, Li X. Biphasic scaffold for annulus fibrosus tissue regeneration. Biomaterials 2008; 29: 643-652.

20 Hoogendoorn RJ, Lu ZF, Kroeze RJ, Bank RA, Wuisman PI, Helder MN. Adipose stem cells for intervertebral disc regeneration: current status and concepts for the future. J Cell Mol Med 2008; 12: 2205-2216.

21 Liu C, Guo Q, Li J et al. Identification of rabbit annulus fibrosus-derived stem cells. PLoS One 2014; 9: e108239.

22 Wang H, Zhou Y, Huang B et al. Utilization of stem cells in alginate for nucleus pulposus tissue engineering. Tissue Eng Part A 2014; 20: 908-920.

23 Feng G, Yang $X$, Shang $H$ et al. Multipotential differentiation of human anulus fibrosus cells: an in vitro study. J Bone Joint Surg Am 2010; 92: 675-685.

24 Henriksson $\mathrm{H}$, Thornemo M, Karlsson C et al. Identification of cell proliferation zones, progenitor cells and a potential stem cell niche in the intervertebral disc region: a study in four species. Spine 2009; 34: $2278-$ 2287.

25 Guo Q, Liu C, Li J, Zhu C, Yang H, Li B. Gene expression modulation in TGFbeta3-mediated rabbit bone marrow stem cells using electrospun scaffolds of various stiffness. J Cell Mol Med 2015; doi: 10.1111/jcmm.12533. [Epub ahead of print].

26 Wang F, Li Z, Lannutti JL, Wagner WR, Guan J. Synthesis, characterization and surface modification of low moduli poly(ether carbonate urethane) ureas for soft tissue engineering. Acta Biomater 2009; 5: 2901-2912.

27 Dong S, Sun J, Li Y, Li J, Cui W, Li B. Electrospun nanofibrous scaffolds of poly (L-lactic acid)-dicalcium silicate composite via ultrasonic-aging technique for bone regeneration. Mater Sci Eng C Mater Biol Appl 2014; 35: 426-433.

28 Farndale RW, Sayers CA, Barrett AJ. A direct spectrophotometric microassay for sulfated glycosaminoglycans in cartilage cultures. Connect Tissue Res 1982; 9: 247-248.

29 Kim YJ, Sah RL, Doong JY, Grodzinsky AJ. Fluorometric assay of DNA in cartilage explants using Hoechst 33258. Anal Biochem 1988; 174: 168-176.

30 Li B, Lin M, Tang Y, Wang B, Wang JH. A novel functional assessment of the differentiation of micropatterned muscle cells. J Biomech 2008; 41: 3349-3353.

31 Sahoo S, Ang LT, Goh JC, Toh SL. Growth factor delivery through electrospun nanofibers in scaffolds for tissue engineering applications. $J$ Biomed Mater Res A 2010; 93: 1539-1550.

32 Vadalà G, Mozetic $P$, Rainer A et al. Bioactive electrospun scaffold for annulus fibrosus repair and regeneration. Eur Spine J 2012; 21: S20-S26.

33 Choi JS, Lee SJ, Christ GJ, Atala A, Yoo JJ. The influence of electrospun aligned poly ( $\varepsilon$-caprolactone)/collagen nanofiber meshes on the formation of self-aligned skeletal muscle myotubes. Biomaterials 2008; 29: 2899-2906.

34 Yin Z, Chen X, Chen JL et al. The regulation of tendon stem cell differentiation by the alignment of nanofibers. Biomaterials 2010; 31: 2163-2175.

35 Li F, Li B, Wang QM, Wang JH. Cell shape regulates collagen type I expression in human tendon fibroblasts. Cell Motil Cytoskeleton 2008; 65 : 332-341.

36 Park K, Ju YM, Son JS, Ahn KD, Han DK. Surface modification of biodegradable electrospun nanofiber scaffolds and their interaction with fibroblasts. J Biomater Sci Polym Ed 2007; 18: 369-382.

37 Schneider T, Kohl B, Sauter T et al. Influence of fiber orientation in electrospun polymer scaffolds on viability, adhesion and differentiation of articular chondrocytes. Clin Hemorheol Microcirc 2012; 52: 325-336.

$38 \mathrm{Li} \mathrm{B}$, Wang JH. Application of sensing techniques to cellular force measurement. Sensors 2010; 10: 9948-9962.

39 Harris AK, Stopak D, Wild P. Fibroblast traction as a mechanism for collagen morphogenesis. Nature 1981; 290: 249-251.

$40 \mathrm{Li} \mathrm{B}$, Wang JH. Fibroblasts and myofibroblasts in wound healing: force generation and measurement. J Tissue Viability 2011; 20: 108-120.

41 Grottkau BE, Yang X, Zhang L, Ye L, Lin Y. Comparison of effects of mechanical stretching on osteogenic potential of ASCs and BMSCs. Bone Res 2013; 1: 282-290.

(1) () $\Theta$ This work is licensed under a Creative Commons Attributioncc) ${ }_{\mathrm{BY}} \mathrm{NC}$ ND NonCommercial-NoDerivs 3.0 Unported License. The images or other third party material in this article are included in the article's Creative Commons license, unless indicated otherwise in the credit line; if the material is not included under the Creative Commons license, users will need to obtain permission from the license holder to reproduce the material. To view a copy of this license, visit http://creativecommons.org/licenses/by-nc-nd/3.0/ 